
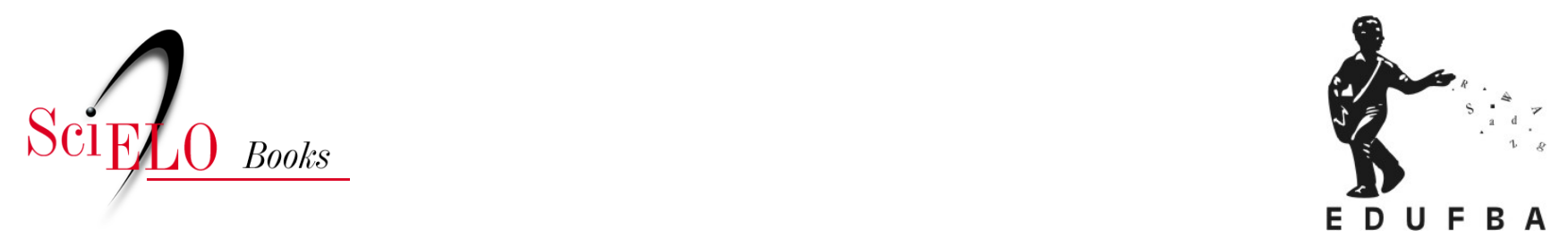

\title{
Sobreposições iconográficas e as estratégias artísticas contemporâneas
}

\author{
Eriel de Araújo Santos
}

\section{SciELO Books / SciELO Livros / SciELO Libros}

SANTOS, E.A. Sobreposições iconográficas e as estratégias artísticas contemporâneas. In:

HERNÁNDEZ, M.H.O., and LINS, E.Á., eds. Iconografia: pesquisa e aplicação em estudos de Artes Visuais, Arquitetura e Design [online]. Salvador: EDUFBA, 2016, pp. 110-123. ISBN: 978-85-2321861-4. https://doi.org/10.7476/9788523218614.0007.

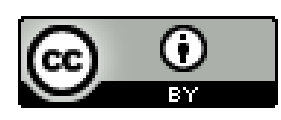

All the contents of this work, except where otherwise noted, is licensed under a Creative Commons Attribution $\underline{4.0 \text { International license. }}$

Todo o conteúdo deste trabalho, exceto quando houver ressalva, é publicado sob a licença $\underline{\text { Creative Commons }}$ Atribição 4.0. 


\section{Sobreposições}

iconográficas eas

estratégias artísticas

contemporâneas

Eriel de Araújo Santos 
ossa memória é um "lugar" onde imagens de um passado vivido e a pulsão escópica do presente se reúnem para constituir nossa percepção. Assim, somos sujeitados a uma carga de informações visuais capazes de influenciar nosso comportamento e a história da humanidade.

Neste texto, abordaremos, a partir da obra Espaço privado, de minha autoria e realizado em 2010, algumas discussões sobre a imagem fotográfica e sua participação como elemento conceitual e técnico em algumas ações artísticas que configuram parte das poéticas contemporâneas.

$\mathrm{Na}$ produção artística atual, percebemos que é recorrente o uso de imagens produzidas, num determinado período da história da arte, nas quais alguns artistas propõem outras maneiras de ver tais imagens, seja pelo uso de tecnologias fotográficas, capazes de alterar suas características visuais, seja por sobreposições de ações, que questionam seu conteúdo iconográfico.

Desde o seu surgimento, a imagem fotográfica tem provocado muitas discussões sobre a representação, em especial atenção para aquelas de caráter figurativo. Com características paradoxais, enquanto vestígio do real ou ficção, a fotografia resulta num achatamento da tridimensionalidade, numa tentativa de tornar visível um determinado instante vivido. 
Ao se aproximar do real, a imagem fotográfica também apresenta outras características. Ela é ícone, mas também índice. Enquanto índice, ela foi, por muito tempo, considerada prova incontestável da verdade. Contudo, as manipulações analógicas e processamentos digitais, cada vez mais eficazes, potencializam essa dualidade e definem resultantes que questionam o tempo e a própria imagem aparente.

O que vemos numa foto parece transportar cenas ou situações de um determinado lugar no passado para o presente, como um portal. Ao reproduzirmos $\mathrm{o}$ ato fotográfico, em tempos distintos de um mesmo lugar, percebemos significativas alterações a cada instante, sejam pelas mutações ocorridas nas coisas que compõem as cenas, sejam pelas alterações dos registros fotográficos, submetidos às diversas temperaturas de cor, definidas pela luz do ambiente. E o que poderíamos dizer quando o resultado de um ato fotográfico procura questionar comportamentos, condutas e fenômenos sociais, ou até mesmo a própria fotografia? Nessa direção, caminham alguns procedimentos artísticos que apresentam distorções iconográficas presentes numa imagem que representam mais do que podemos ver.

A representação, por sua vez, é considerada como um dos campos de investigação da iconografia, a qual amplia e problematiza a realidade a partir de ações artísticas que põem em discussão e análise um fato ou situação representada pela fotografia, por exemplo. Muitas vezes, não se representa algo apenas do imaginário ou simbólico, mas também do real. Na contemporaneidade, percebemos que as poéticas se encerram no indivíduo, pois afastam-se das escolas e instituições detentoras de regras pré-estabelecidas. Assim, em cada projeto artístico, verificamos que são acrescentados dados históricos, conceituais, teóricos, técnicos e pessoais. Neste sentido, uma certa atitude artística pode, não necessariamente, criar uma nova imagem, mas também reproduzir algo já conhecido, uma ação de repetição que acrescenta dados sutis ou mesmo invisíveis numa determinada imagem.

Lembramos, por exemplo, do trabalho produzido por Sherrie Levine, que fotografou fotos tiradas por Walker Evans. Levine manteve a mesma qualidade fotográfica conseguida por Walker. Assim, ela nos mostra uma imagem onde não vemos suas escolhas para compor a foto, pois já haviam sido definidas por Walker. A sobreposição aqui está relacionada com o ato feminino sobre um ato masculino. Dessa maneira, a artista parece reivindicar respeito e reconhecimento da sociedade, predominantemente definida pelos feitos masculinos.

Ao fotografar fotografias, Levine escolhe sobrepor tempos para uma mesma imagem. Mais do que isso, ela busca construir uma hipótese desconstrutivista, usando modos de simulação e apropriação. Como ela afirma: "Escolho imagens que manifestam o desejo de que natureza e a cultura nos oferecem uma impres- 
são de ordem e significado". (LEVINE apud BAQUÉ, 1998, p. 152) Com esse trabalho, Sherrie Levine estabelece um duelo com a aura fotográfica e a luta com o não visto, denunciando o poder "falocêntrico" da arte. Assim:

A apropriação e a releitura que a fotografia artística contemporânea faz das imagens também são realizadas pelo cotejo de fotos existentes, normalmente vernáculas e anônimas, para a composição de grades, esquemas e justaposições. Em certa medida, o papel do artista, nesse caso, é como o de um editor de gravuras ou de um curador, configurando o significado das fotos por meio de atos de interpretação e não pela realização de imagens. (COTTON, 2010, p. 208)

Os artistas Arnulf Rainer e Carmen Calvo, por sua vez, sobrepõem camadas de tinta ou objetos sobre imagens fotográficas. Esses artistas buscam produzir outros direcionamentos para a leitura e a fruição da imagem fotografada. Ambos constroem uma obra de caráter político, pois, a cada elemento icônico sobreposto às imagens fotografadas, são acrescentadas características de significado irônico, perverso ou mesmo antagônico à cena registrada.

Carmen Calvo, por exemplo, produz uma obra de caráter híbrido, cuja investigação constrói uma identidade subjetiva e, ao mesmo tempo, histórica, associada à memória correspondente aos objetos escolhidos. Para Calvo, interessa o retrato anônimo, desprovido de uma identidade reconhecida. Quando realiza sobreposições de cores e formas, propõe acrescentar dúvidas sobre uma determinada imagem fotográfica. É importante destacar que suas intervenções, na maioria das vezes, se estabelecem na área do rosto retratado, anulando a identidade e acrescentando outros significados de caráter associativo aos materiais escolhidos, como o metal presente na obra La poesia está en otro sítio, ou o tecido e a tinta sobre a fotografia, aplicados na obra No es lo que parece. Assim, ela troca identidades grafadas pela luz por uma obra questionadora sobre a humanidade e suas direções políticas.

Enquanto isso, Arnulf Rainer investe em procedimentos que marcam as imagens fotográficas a partir de técnicas tradicionais, como pintura e gravura. Quando interfere com a ponta seca numa foto, por exemplo, ele procura estabelecer nexos entre as imagens fotográficas e a violência surgida das guerras, ou comportamentos agressivos que a humanidade estabelece diariamente nas grandes cidades. Para tanto, algumas vezes, Rainer escolhe sua própria imagem para compor as cenas e construir sua obra. Ele usa o autorretrato como referência

1 "Elijo imágenes que manifestan el deseo de que la naturaleza y la cultura nos aporten una impresión de orden y de significación”. 
para falar daquilo que o corpo vê e sente, em especial atenção para os estados emocionais extremos. A crucificação, ou mesmo a representação da cruz, é um dos símbolos encontrados em pinturas e intervenções fotográficas produzidas por ele. Sua escolha, talvez, esteja ligada ao significado amplo desse elemento, que se faz presente em vários ciclos do homem na Terra.

Ao lembrar-nos do elemento iconográfico em forma de cruz, observamos que ele é usado para representar a vida e a morte em vários momentos da história, além de outras cargas simbólicas associadas ao mesmo. No campo religioso, esse símbolo arrasta o tempo consigo e as muitas religiões que creem no cristianismo, ou mesmo aquelas que o hostiliza. O estudo iconológico desse símbolo atravessa vários campos do conhecimento humano, aportando inúmeros significados, além de sobrepor a outros significantes. Dessa maneira, o cruzamento ortogonal de duas retas parece alcançar significações até então desconhecidas da natureza humana e dos materiais, encontrando sentido de estar na natureza das imagens.

Neste texto, procuramos fazer uma pequena genealogia da iconografia como método de trabalho artístico e tratar das suas possíveis contribuições nas poéticas que articulam apropriações, mestiçagens e hibridações com imagens fotográficas e o tempo. Assim como a cruz, vários outros elementos, como as marcas usadas por grandes empresas, materiais ou substâncias que alteram as características físicas e visuais de uma imagem, são usados em práticas artísticas para propor e discutir os significados de sobreposições e contaminações interculturais.

Rosangela Rennó, em seu projeto A última foto, trabalhou com um ícone religioso, a imagem do Cristo Redentor, marco simbólico da cidade do Rio de Janeiro. Essa representação se tornou um ícone turístico e, como souvenir, criou uma relação econômica de exploração da imagem, resguardada pelos valores agregados ao mesmo. A obra criada pela artista faz refletir sobre os direitos de exploração da imagem pela Arquidiocese do Rio de Janeiro e a popularização da produção de imagens fotográficas digitais. Para Rennó, a discussão sobre a extinção da imagem icônico-indicial está associada também à popularização e à facilidade que as imagens digitais trouxeram para o cotidiano das pessoas.

Com a popularização da produção de imagens, é inevitável o surgimento de novos meios de divulgação e compartilhamento dessa produção. Assim, novos produtos culturais aparecem em meio aos repertórios de imagens criadas e postas em circulação, surgindo, então, uma "civilização da imagem”. (DURAN, 2010) O comportamento e os modos de vidas, até então desconhecidos, dão lugar a uma compreensão alargada do "estado social". Neste sentido, Rosangela Rennó vem construindo uma obra que faz vir à tona alguns aspectos esquecidos de algumas histórias sociais. Ela se apropria de acervos fotográficos, muitas vezes esquecidos pelo tempo, e atualiza-os em mostras que discutem a existência da lembrança e da memória, mesmo que duvidosas. 
Artistas revisitam apócrifos, ou mesmo uma vulgata, para detonar uma atualização ou desvios de significados existentes numa imagem. Com isso, criam dinâmicas em que o passado e o futuro se encontram nas representações. A fotografia é reordenada em uma espécie de neopicturialismo, pois "trata de recunciar as separações para pensar a obra como uma mestiçagem de práticas e materiais, como uma articulação do objetivo e do subjetivo". (BAQUÉ, 2003, p. 148) Para ilustrar alguns trabalhos que são norteados por tais procedimentos, citaremos alguns exemplos.

O artista Joseph Kosuth põe lado a lado categorias da representação: o objeto, sua imagem e seu significado, descrito na língua correspondente, onde o mesmo se encontra em exposição. Dessa maneira, Kosuth faz roçar entre si as representações de um mesmo. Além disso, são sobrepostas algumas características da forma, luz, cor e ambiência do lugar onde a obra é apresentada. Assim, essas características, quando absorvidas pela proposta, transfiguram o signo.

Paralelamente, Rennó e Kosuth justapõem categorias da representação iconográfica e conduzem a arte para direções do fazer ver. Em $A$ última foto, Rennó coloca, lado a lado, a última imagem fotográfica produzida por uma câmera fotográfica analógica e a própria máquina. Enquanto isso, Kosuth estabelece aproximações entre imagens, conceitos e objetos. Essas práticas artísticas estabelecem conexões entre o real e o simbólico, o objeto e suas imagens, o Eu e as coisas.

Ao falar de algumas qualidades inerentes aos objetos e materiais, ou mesmo daquelas definidas verbalmente pela humanidade, Joseph Kosuth cria estratégias para transferir a responsabilidade da ideia para a obra de arte. Nessa direção, Kosuth estabelece uma contingência entre o significado e as possíveis sobreposições plásticas, visuais ou conceituais. Em suas obras, ele recorre à luz neon, por exemplo, para indicar as qualidades da cor e seu significado visual e verbal. Em outros trabalhos, a imagem fotográfica é usada para indicar sua relação com o tempo e o lugar.

Em 1990, Kosuth produziu uma obra, No number \#3 (+216, after Augustine's Confession), em que sobrepôs, em diferentes posições, três placas de vidros transparentes; as placas possuíam dimensões distintas e, sobre cada uma, existia um mesmo texto escrito numa mesma fonte, mas apresentando tamanhos variados: "Eu realmente vejo algo diferente a cada vez, ou eu somente interpreto o que vejo de uma maneira diferente? Estou inclinado a aceitar o primeiro. Mas por quê? - interpretar é pensar, construir algo; ver é um estado".

2 "trata de renunciar a las separaciones para pensar la obra como un mestizaje de prácticas y de matérias, como articulación de lo objetivo y de lo subjetivo".

3 "Do I really see something different each time, or do I only interpret what I see in a different way? I am inclined to say the former. But why? - To interpret is to think, to do something; seeing is a state". 
Ao destacarmos essa obra, verificamos a pertinência do texto usado sobre as placas de vidro e as estratégias usadas por alguns artistas contemporâneos, pois, ao apresentar um novo resultado de suas investigações poéticas, a maioria dos artistas procura instaurar um "estado de arte", mesmo quando esse "estado" cria uma diferença na repetição de uma determinada imagem-obra. Em 2005, Kosuth produziu a obra Mondrian's work I, na qual ele sobrepôs textos e luz neon sobre a reprodução de uma pintura de Piet Modrian. Naquele momento, as sobreposições criaram contaminações e desvios do nosso olhar para além da pintura, mas mantendo-a próxima e inabalável, pois:

Existe um intermediário entre a imagem e o conceito: é o signo, desde que sempre se pode defini-lo da forma inaugurada por Saussure a respeito dessa categoria particular que formam os signos linguísticos, como um elo entre uma imagem e um conceito, que na união assim estabelecida, desempenham respectivamente os papéis de significante e significado. (LÉVI-STRAUSS, 1989, p. 33)

A reapresentação ou reestruturação de uma obra já realizada parece fazer parte de muitas práticas artísticas contemporâneas. Com isso, gostaria de destacar, além daqueles já mencionados aqui, dois artistas que vêm construindo uma obra em direção ao conceito do duplo. Contudo, o surgimento desse "outro" corresponde a um duplo metamorfoseado por meio de ações performáticas, processamentos digitais e escolha de materiais e objetos até atingir o momento do ato fotográfico e surgir um "duplo" pela diferença.

Vik Muniz é um artista que finaliza seu processo criativo com o ato fotográfico, apresentado sobre papel fotográfico. Contudo, para compor uma imagem escolhida, ele seleciona objetos, materiais e procedimentos técnicos a serem usados na reconstrução de uma imagem extraída da história da arte, por exemplo. Dessa maneira, ele tenta promover um encontro entre o passado e algumas situações sociais ou culturais da atualidade. Como ele afirma, "nossa capacidade para pesquisar o mundo das formas e da informação de maneira organizada tem contribuído enormemente para nossa aptidão de imagens dentro de imagens". (MUNIZ, 2007, p. 35) Talvez, seja essa uma metodologia que acompanha a humanidade e estabelece ligações entre os fatos para construir o elo entre tempos distintos. Assim, o homem projeta sua compreensão do mundo físico e psíquico por meio das imagens. Porém, essa compreensão está sujeita às associações que criamos com experiências vividas ou imaginadas.

A acumulação é uma operação que faz parte dos procedimentos fundamentais da obra de Vik Muniz (2007), mas é importante destacar que a escolha dos materiais para essas operações mantém uma relação interpretativa da história ou de fatos vividos, configurados numa cena preparada para o ato fotográ- 
fico. As sobreposições resultam de somas de conceitos, das qualidades formais e cromáticas dos materiais envolvidos, relatos do cotidiano, histórias pessoais, fatos históricos ou mesmo apropriação de outras representações artísticas.

O artista chinês Wang Qingsong, por sua vez, produz uma obra que busca refletir sobre uma radical transformação política, econômica, social e cultural que vem atravessando seu país. Ele apresenta, em suas imagens, a indignação quanto à modificação da aparência das cidades e da vida cotidiana existentes na China. Para isso, Qingsong utiliza colagens e montagens digitais para compor cenas que discutem a perda dos valores tradicionais e destacam as contradições surgidas da hibridação entre o pensamento budista e o capitalismo.

Em duas de suas obras, podemos visualizar a ênfase dada aos procedimentos de sobreposição de ícones de culturas distintas numa mesma imagem. Estou me referindo às obras Tbinker (fotografia, 180 x $90 \mathrm{~cm}$, 1998) e Requesting Buddha (fotografia, $180 \times 110 \mathrm{~cm}, 1999)$. Nesses trabalhos, o artista usa a imagem do seu próprio corpo para representar posições iconográficas da filosofia oriental, especificamente aquelas relacionadas ao budismo e à influência do consumo, ao contaminar tais comportamentos.

Na representação da compaixão, Avalokiteshvara, ele mesmo aparece numa imagem, em posição sentada, como um bodhisattva de vários braços, nos quais segura objetos da sociedade de consumo. Intitulada Requesting Buddha, essa obra procura atender algumas inquietações de Quigsong, pois está associada às fusões de procedimentos pictóricos, performáticos, instaurações conceituais e ao próprio ato fotográfico.

Amalgamados à própria imagem, a partir de procedimentos digitais, a obra Thinker reúne imagens de outros elementos à sua própria imagem alterada. A modificação realizada apresenta o artista em posição de meditação, onde ele critica um dos maiores ícones da cultura do consumo em fast food, a famosa marca "M" da empresa McDonald's, que aparece como uma tatuagem em baixo relevo, marcada na área peitoral de Quingsong. A ironia desse trabalho posiciona o fruidor para as relações da arte com o comportamento humano e suas digressões culturais. Uma transfiguração que atinge o olhar e nos faz pensar sobre o mundo e suas transformações. Assim, lembra Arthur Danto (2005, p. 222) sobre uma recomendação de Leonardo da Vinci:

Imaginem, propõe Da Vinci, que se interponha um painel de vidro entre o artista e seu tema. O contorno do tema, tal como traçado no vidro, irá reproduzir exatamente o contorno do tema tal como se apresenta ao olho, e se adicionalmente reproduzimos no vidro todas as características do tema conforme vistas através do vidro o olho acabará se tornando incapaz de discriminar entre a percepção do objeto e a percepção da sua réplica no vidro interposto. 
A interposição do fluxo da vida sobre as representações iconográficas das obras de arte amplia nossa percepção e aproxima tempos, lugares e imagens arquivadas em nossa memória. Verificamos, então, após as análises dos exemplos realizados até aqui, que na dinâmica existente nos processos artísticos contemporâneos, quando usam a fotografia como elemento norteador de uma poética, a imagem resultante pode apresentar características de acumulação, tornando-se uma imagem de imagens. Pensando dessa maneira, venho construindo obras de caráter transitório, nas quais a imagem se altera a todo instante. Para este texto, destaco uma produção artística na qual uso elementos reflexivos: ouro branco e vidro. Dessa maneira, a imagem estará sendo sobreposta a outras imagens-reflexos, acompanhando o tempo, as coisas e ações que acontecem ao seu redor.

Ao fotografar o signo ótico, este se apresenta inteiramente objetivo, afastado de qualquer subjetivismo, como afirma Shaeffer (1996). Nas obras fotográficas dos construtivistas, por exemplo, percebemos uma fotografia inventiva. Nelas, aparecem um arranjo formal promovido pelo direcionamento das lentes nas mais variadas perspectivas descentralizadas e pontos de vistas incomuns. Em alguns trabalhos que desenvolvo, observo que os procedimentos de sobreposição e espelhamento das imagens redirecionam a objetividade fotográfica para um estado de maior incerteza, aproximando o ato fotográfico de uma subjetividade instaurada na imagem resultante.

Desde 2003, venho desenvolvendo uma pesquisa de caráter prático e teórico, norteada pelo pensamento do retorno da imagem à situação ou ao material que lhe deu origem, nos quais são somadas características físicas e químicas à imagem produzida fotograficamente. Nos procedimentos adotados, por sua vez, os processos fotográficos são redirecionados para outros campos da produção artística, nos quais a imagem é revelada ou fixada por princípios técnicos em que a fixação da imagem se dá por calor, e não por radiação luminosa, por exemplo.

O espelhamento é um procedimento que exploro junto às imagens fotográficas, podendo ocupar o lugar como representante ou representado. Quando sobreponho imagens fotográficas realizadas a partir de superfícies espelhadas, apresentadas no próprio espelho, proponho um desdobramento das imagens junto ao tempo e aos instantes capturados numa superfície maculada por um passado fotografado. Surge, então, uma fotografia de caráter duvidoso, pois estará sempre contaminada pelo presente.

Ao considerar o mundo como ilusão, poderíamos pensar sobre o espectro do visível, que define nossas observações visuais. Na mitologia grega, Apate era um espírito que personificava o engano, o dolo e a fraude. Foi um dos espíritos que saíram da caixa de Pandora. Assim, podemos estudar alguns procedimentos artísticos que se caracterizam por uma configuração ou reconfiguração do estado 
das coisas. O espelho é um elemento que nos faz pensar sobre o presente e sua relação com nosso cotidiano público e privado, pois ele capta instantes e instaura uma verdade duvidosa.

Podemos afirmar que a reflexão não é apenas um processo físico, uma reprodução passiva da imagem, mas uma dinâmica presente no que vemos. Olhar, não apenas para captar a imagem de um objeto ou situação, mas, também, como exercício intelectual, já que em toda forma de conhecimento humano existe um retorno. Talvez seja dessas construções que tanto elaboramos como somos elaborados.

Ao construir possibilidades visuais de uma existência, a arte propõe uma espécie de alargamento da ideia de realidade. Mesmo com o surgimento da fotografia como uma espécie de espelhamento do real, quando esta promove uma ideia irrefutável do seu valor documental, seguimos questionando aquilo que vemos, seja por meio de uma imagem, seja pelos fatos observados diretamente.

Quando olhamos uma foto, pensamos na sua origem: local e período em que foi realizada. Contudo, podemos usar métodos de análises iconológicas, iconográficas ou mesmo científicas, confrontando sua fragilidade existencial e semântica. Assim, ao colocar uma imagem fotográfica em situações de "risco", os conceitos operados e as imagens apresentadas estão sempre se refazendo. Dessa maneira, a transitoriedade física e conceitual de uma imagem instaura uma espécie de dinâmica na imagem fixa.

Ao escolher uma imagem para compor um trabalho, procuro criar uma situação de instabilidade visual entre o que vemos e o que aconteceu. Penso que uma imagem fotográfica está associada às características físicas presentes na sua estrutura, assim como aos estados psíquicos atuantes no "êxtase fotográfico", definido por Roland Barthes (1984). Ao subverter a ordem dada pela fotografia clássica, na qual o assunto da imagem deveria permanecer imobilizado para uma fruição de algo "morto", proponho alterar a representação fotográfica para que esta possa refletir o presente na sua própria estrutura física.

Originalmente, a imagem escolhida como referência para elaboração da obra Espaço privado carrega em sua composição uma profusão de imagens, multiplicadas pelo espelhamento. O local escolhido foi um banheiro público, localizado num shopping center, na cidade de Porto Alegre.

Um dos fatores que me chamou a atenção, além da instabilidade do olhar, provocado pelos multidirecionamentos dados pelos rebatimentos das imagens espelhadas, foi a composição cromática presente nos elementos da cena (Figura 1), estabelecidos praticamente em tons de prata e branco, seja pelos metais e espelhos, seja pelo revestimento cerâmico, bancadas e pisos em mármore branco. 


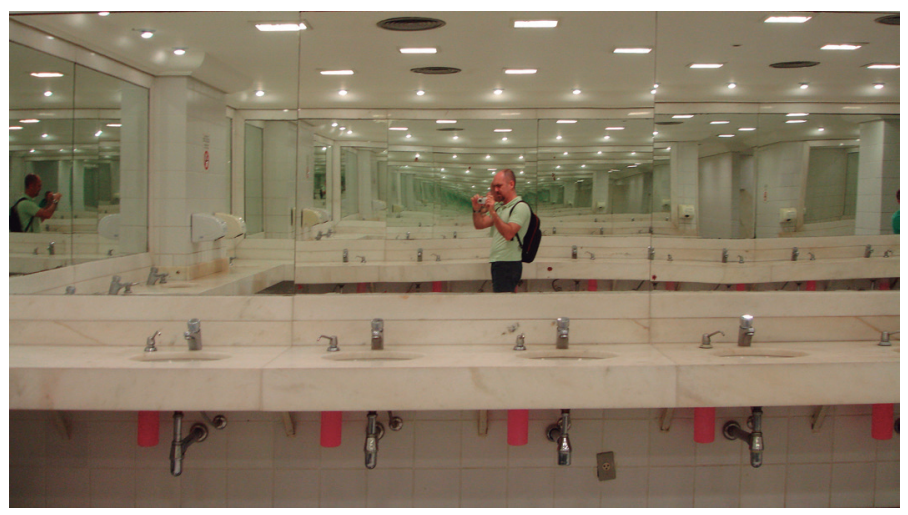

Figura 1 - Imagem do interior do banheiro, no Shopping Praia de Belas, em Porto Alegre Fonte: elaborado pelo autor.

A partir dessa imagem, recorri aos procedimentos técnicos específicos para produzir uma imagem elaborada em prata sobre branco, procurando estabelecer relações entre a imagem e sua referência de origem. Para alcançar tal resultado, usei a técnica de transferência de imagens com utilização de pigmentos minerais sobre superfícies vitrificadas. Neste caso, uma pasta preparada com ouro branco, aplicada sobre cerâmica vitrificada. A imagem final resultou da soma de procedimentos digitais, preparação reticular da imagem e posterior construção de uma matriz serigráfica, finalizada com sua transferência em placas de porcelana (substituta do papel fotográfico). A fixação da imagem se deu a uma temperatura de 740 graus centígrados, sobrepondo ouro sobre vidrado.

Os procedimentos adotados para adquirir uma imagem espelhar nos remetem ao passado histórico da fotografia, quando a imagem era produzida sobre uma placa de vidro. Para tanto, iniciei meus experimentos reproduzindo uma das imagens encontradas no livro de fotografia O lápis da natureza, elaborado por William Henry Fox Talbot. Escolhi a chapa III, de autoria do fotógrafo, para realizar o teste da imagem de sua coleção de porcelanas, agora reproduzida por mim e apresentada em prata sobre branco, com uso da platina, como metal substituto da prata.

O abismo na imagem alcançado no trabalho Espaço privado une dois conceitos operacionais que venho explorando: 1) o retorno da imagem ao tipo de material presente em sua composição e 2) a investigação de novos meios materiais para apresentação fotográfica. Assim, o papel fotográfico foi substituído pela superfície lisa e brilhante dos azulejos, presentes na imagem do banheiro referente.

A imagem final diz respeito a um detalhe da foto registrada do banheiro, correspondente ao espaço ocupado por um conjunto formado por 36 peças de azulejos brancos (Figura 2), medindo 15 x $15 \mathrm{~cm}$ cada. A escolha do enquadramento fotográfico, a partir do espelho do banheiro, traduz a instabilidade da imagem encontrada no lugar, onde o público e o privado se encontram numa mesma superfície. 


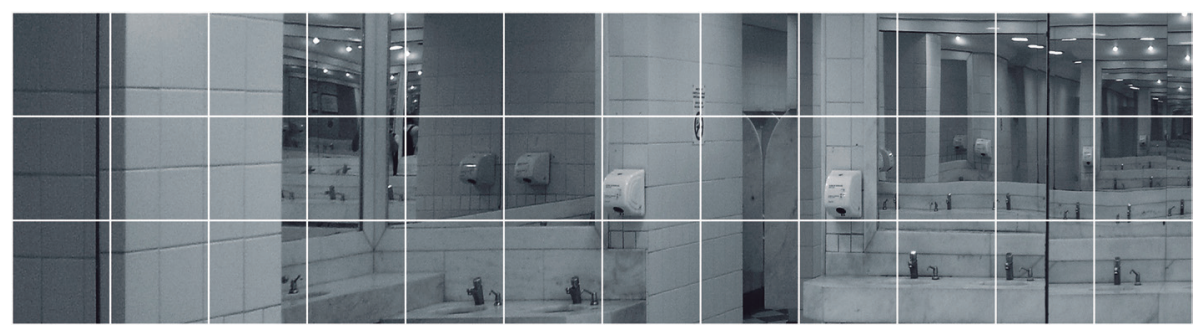

Figura 2 - Sequência estrutural dos azulejos usados na produção da imagem-espelho.

Fonte: elaborado pelo autor.

Tal proposta esbarra em questões advindas da nossa memória e comportamento social, pois, ao estarmos num determinado espaço social, surge um confronto entre o indivíduo e sua condição sociocultural. Ao incorporar as imagens na superfície branca dos azulejos, por meio de fixação que garante um estado de permanência, instaura-se uma condição de instabilidade da imagem, na qual o espelhamento da superfície polida e brilhante do azulejo branco soma-se às características apresentadas pela imagem em platina e sua característica especular. Dessa maneira, a obra adquire características de representação do devir na imagem e da interpretação do reflexo.

A retícula que compõe a imagem fotografada agora se apresenta em reflexo (Figura 3), como se fosse possível fundir tempos e espaços numa imagem estática. Assim sendo, como explica Rivera (2003, p. 187), diferentes estratégias mostram que um importante desafio da arte contemporânea consiste, eu diria, em construir representações capazes de criticar sua própria natureza representacional - colocá-la radicalmente em crise, rompê-la em prol de algo que Foster não ressalta, mas me parece essencial: uma certa presença traumática do sujeito.

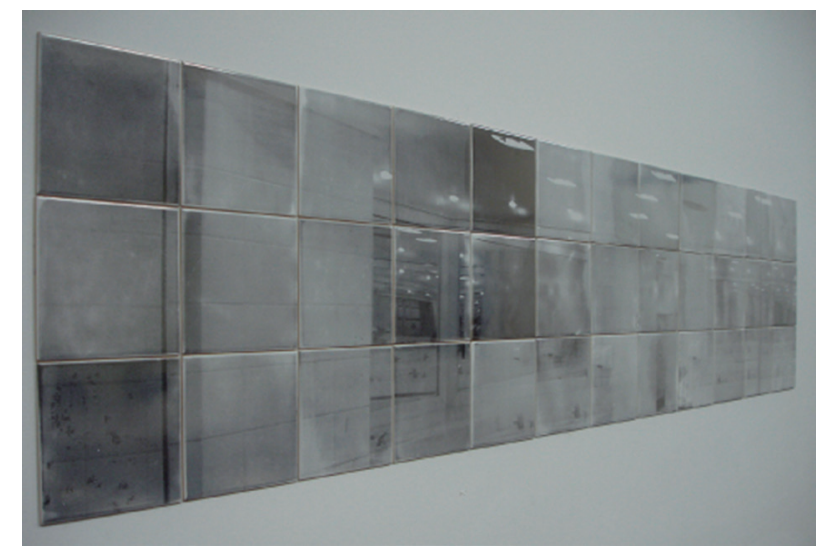

Figura 3 - Espaço privado

Fonte: elaborado pelo autor. 
Assim, ao representar uma imagem fotográfica, onde a sombra é apresentada como um elemento refletor (Figura 4), proponho a participação do tempo numa imagem fixa, alinhando-se à "imagem-furo", que busca ir além da representação de um instante, alcançando, dessa maneira, a fugacidade da percepção numa poética do acontecimento em imagens.

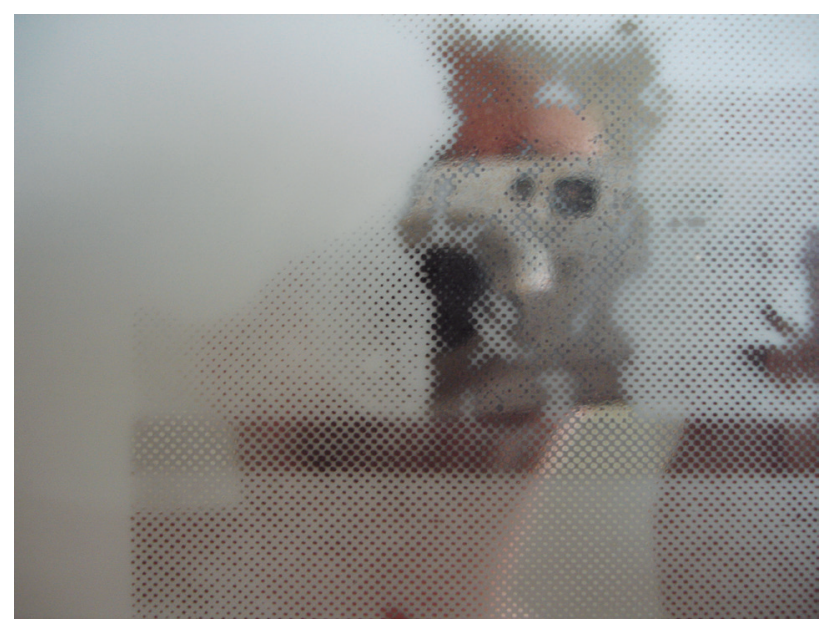

Figura 4 - Detalhe da obra "Espaço privado" Fonte: elaborado pelo autor.

\section{Referências}

BAQUÉ, D. La fotografía plástica:un arte paradójico. Barcelona: Gustavo Gili, 2003.

BARTHES, R. A câmara clara. Rio de Janeiro: Nova Fronteira, 1984.

COTTON, C. A fotografia como arte contemporânea. São Paulo: Martins Fontes, 2010.

DANTO, C. A. A transfiguração do lugar-comum: uma filosofia da arte. São Paulo: Cosac Naify, 2005.

DURAN, G. O imaginário: ensaio acerca das ciências e da filosofia da imagem. Rio de Janeiro: DIFEL, 2010.

LÉVI-STRAUS, C. O pensamento selvagem. Campinas: Papirus, 1989.

MUNIZ, V. Reflex: Vik Muniz de A a Z. São Paulo: Cosac Naify, 2007.

RIVERA, T. O avesso do imaginário: arte contemporânea e psicanálise. São Paulo: Cosac Naify, 2013.

SCHAEFFER, J.-M. A imagem precária. Campinas. Papirus, 1996. 